\title{
Evaluation of Typhoon Disaster Losses of Hainan Island Rubber Plantation
}

\author{
Jinghong Zhang ${ }^{1,2}$, Haijing Huang ${ }^{1,2}$, Xiufen Che ${ }^{1,2}$, Mingjie Zhang ${ }^{1,2}$ \\ ${ }^{1}$ South China Sea Meteorology and Disaster Mitigation Research Key Laboratory, Haikou 570203, \\ China \\ ${ }^{2}$ Climate Center of Hainan, Haikou 570203, China
}

\begin{abstract}
Hainan Island is selected as the study area, which is the main base of natural rubber production. In this research, according to the analysis and study of the cause of rubber wind disaster, parameters in the evaluation model was determined with statistics method based on the environment background and the typhoon disaster database. The extension model of rubber wind disaster evaluation for Hainan Island was build based on extension theory. The wind disaster of 1117 Severe typhoon "NESAT" was evaluated for rubber plantation of Hainan Island.
\end{abstract}

Keywords: Hainan island rubber plantation tropical cyclone disaster evaluation

\section{Introduction}

In China, the rubber plantation is mainly distributed in Hainan, Yunnan, Guangdong, Guangxi and Fujian Province. Among them, Hainan is one of the main natural rubber production bases of China, its rubber planting area reaching 7.3559 million mu in 2010. Hainan rubber plantation belongs to the tropical north-edge island type, and is susceptible to the tropical cyclone ${ }^{[1-2]}$. The wind damage resulting from the tropical cyclone is the most tremendous natural disaster facing rubber industry in Hainan industry.

Yang Shaoqiong ${ }^{[3]}$ et al. analyzed the

基金项目: 国家自然科学基金(41465005, 41265007); 海南省气象局青年基金 (HNQXQN201501) influence thrown on rubber trees by typhoon from the view of physiology of wind-damaged tree. Luo Jiaqin ${ }^{[4]}$ et al. studied the influence on rubber of No.9207 strong typhoon. Li Zhiquan ${ }^{[5]}$ analyzed the influence of typhoon Damrey on the rubber production in Hainan reclamation zone in 2005 . Yu Wei ${ }^{[6]}$ et al. analyzed the damage caused to rubber industry in Hainan cultivated landing and the subsequent reflections concerning the rubber industry development. Zhou Zhifeng ${ }^{[7]}$ et al. analyzed the characteristics of tropical cyclone landing in Hainan Island and the influence of tropical cyclone on the rubber production of Hainan reclamation zone. The disaster evaluation model is established with the fuzzy mathematics method for tropical cyclone disaster evaluation by both domestic and overseas scholars ${ }^{[8-12]}$. Research has been made into the grading of hazard level of cyclone disaster. The objective analysis method is used for quantitatively evaluating the concrete data of disaster losses, and the statistical analysis and evaluation is performed over the tropical cyclone disaster mainly in light of the disaster-inducing factors such as strong wind and rainstorm ${ }^{[13-15]}$. Tropical cyclone (especially the resulting strong wind) is a complicated problem when it comes to the evaluation of the impact evaluation on rubber. The impact factors not only include the intensity of tropical cyclone itself, but also other factors like cyclone route, landing location, underlying surface topography and the rubber cultivation condition. Moreover, there is no truly universal 


\section{Risk Analysis and Crisis Response in Big Data Era (RAC-16)}

model for the evaluation of the impact of wind damage on rubber.

In this research, Hainan Island, the area frequently attacked by wind damage, is chosen to carry out the typical research. The data from advanced surface weather observation network are used to obtain the encrypted weather data, playing a guiding and demonstrating role for the rubber plantation of other regions. By publishing the wind damage information of rubber, the governments and the relevant departments can quickly and macroscopically obtain the damage area and the degree of Hainan rubber to formulate the scientific and reasonable emergence plan and preventive measures. Such information is important for achieving the goal of disaster preventing and control as well as high and stable production, and enhancing the robustness of rubber industry to the tropical cyclone disaster.

\section{Data Sources}

In this research, the historical weather data and disaster data of typhoon from 1950-2010 are obtained from Hainan weather station; GDP data of Hainan are obtained from Hainan Yearbook 1980 2010. In this research, basic geographic information data like Hainan 1:50 000 topographical map and Hainan 1:50000 digital evaluation model (DEM) are from Hainan Bureau of Surveying and Mapping.

\section{Establishment of the Evaluation Model}

\subsection{Selection of the involved factors}

According to this research, the evaluation factors are determined as topographical factor, rubber factor and the weather factor.

\section{(1) Topographical factor}

It can be found in this research that due to the redistribution effect on the wind power by terrain and topography, a diversity of topographies and landform conditions, such as canyon, bellmouth, mountain trough line, slope and slope positions lead to great variation of wind damage. Therefore, the effect of topography must be fully considered in the evaluation of wind damage of rubber plantation. According to analysis of massive research data, the influence of topographic factor on the wind damage is generally mastered. Four main factors, namely, slope surface, slope position, slope and special topography are selected, and the model is constructed to obtain the topographic comprehensive index of rubber.

(2) Rubber factor

Rubber factor is a combination of a series of indexes correlated to the physiological and ecological characteristics of rubber. It can be expressed as rubber comprehensive index. The higher the index, the higher the vulnerability is, and the more severe the wind damage is. According to the investigation and the research result of disaster caused by typhoon Damrey to rubber, several indexes related to the wind resistance of rubber, such as species, planting mode, planting density, shaping and pruning are selected. Because the wind damage to different plant materials is not significantly different, this effect is not considered. The integrity degree of the shelterbelt plays an important role in reducing the rubber wind damage, so it is listed as one of the rubber factors.

(3) Weather factor

The wind damage of rubber plantation is mainly resulted from the strong wind and the rainstorm caused by tropical cyclone. According to the large-scale statistical analysis of Hainan rubber damage data that have been collected and sorted, the synergistic effect of rainfall is considered to establish the weather comprehensive index.

Weather comprehensive index $=W_{\mathrm{m}}^{\alpha} \times W_{\mathrm{a}}^{\beta} \times \operatorname{TR}^{\gamma}$.

Where $\mathrm{Wm}$ is the maximum wind velocity, $W_{a}$ is the average wind velocity, TR is the total rainfall and $\alpha, \beta, \gamma$ represent the weight coefficients of these three factors, respectively. As rainfall and 
wind data usually come from limited observation of weather stations, the spatial distribution can be influenced by many kinds of topographic factors. The position of weather stations and its density are restrained by the topographic condition as well. So interpolation will be performed to formulate the continuous distribution information.

\subsection{Wind damage grading standard of rubber plantation}

In order to represent the level of wind damage of Hainan Island rubber plantation and to enable an intuitive knowledge of the hazard level, five-grade method is used in this research to express the magnitude of wind damage of regional rubber plantation. The wind damage grading standard has to be scientific and concrete and in line with reality, and provide reference to the weather disaster evaluation. Predecessors have made some researches on the losses of rubber tree caused by typhoon, and laid down the grading standard of wind damage of rubber tree. Based on the historical disaster data and the research achievement, the wind damage grading standard of rubber plantation in Hainan Island is formulated (Table 1). correlation function of wind damage evaluation is established, and the weight coefficient is determined with the principal component analysis in accordance with the historical disaster data of rubber plantation. The classification is determined by calculating the correlation degree. Finally, the evaluation result of the rubber plantation wind damage is presented by GIS visualization representation.

\section{Evaluation case}

\subsection{Evaluation of the influence of No.1117 strong typhoon Nesat on rubber plantation in Hainan Island}

\subsubsection{General situation of wind and storm}

No. 17 strong typhoon Nesat in 2011, which has the characteristics of strong intensity, quick movement speed and great influence, is the next strongest typhoon after typhoon Damrey in the last 6 years. Under its influence, a strong rainfall and a strong wind occurred in Hainan province. Rainstorm occurred in Hainan Island on an extensive scale during the influence period (20:00 of 28th to 20:00 of 30th of September). The cumulative rainfall of automatic stations of

Table 1. The wind damage grading standard of rubber plantation.

\begin{tabular}{llll}
\hline Level & The wind damage rate & Broken and flattened rate & Description \\
\hline 0 & $0.0 \%$ & $0.0 \%$ & Undamaged \\
1 & $\leq 10.0 \%$ & $0.0 \%$ & Slight wind damage \\
2 & $10.0 \%-20.0 \%$ & $\leq 5.0 \%$ & Moderate wind damage \\
3 & & $\leq 20.0 \%$ & Severe wind damage \\
4 & & $\leq 40.0 \%$ & Very severe wind damage \\
5 & & $\geq 60.0 \%$ & Standard of judging rubber plantation \\
& & & worthless \\
\hline
\end{tabular}

\subsection{Establishment of the valuation model}

According to the extension theory, the standard matter-element model for the wind damage evaluation of Hainan rubber plantation is first constructed to determine the typical area and the partial area (Table 2). Then the
92 villages and towns exceeded $250 \mathrm{~mm}$, and that of 3 villages and towns exceeded $500 \mathrm{~mm}$. The biggest rainfall occurred in the automatic station of Wangxia Township Government, Changjiang county, with a rainfall of $904.6 \mathrm{~mm}$. Great wind above level 8 occurred in 284 villages and towns of Hainan Island; great wind 
Risk Analysis and Crisis Response in Big Data Era (RAC-16)

Table 2. The matter-element model for wind damage evaluation of rubber plantation

\begin{tabular}{|c|c|c|c|c|c|c|}
\hline Level & $\begin{array}{l}\text { Wind damage } \\
\text { rate of rubber }\end{array}$ & \multicolumn{3}{|c|}{ Element characteristic } & \multicolumn{2}{|c|}{ Standard matter-element } \\
\hline 1 & $<0.05$ & \multicolumn{3}{|c|}{$\begin{array}{l}\text { The rubber comprehensive index is less than } 0.131 \\
\text { The topographic comprehensive index is less tha } \\
0.406\end{array}$} & $R_{1}=$ & {$\left[\begin{array}{l}<0,0.131> \\
<0,0.406> \\
<0,0.226>\end{array}\right]$} \\
\hline \multirow[t]{3}{*}{2} & $0.05 \sim 0.1$ & \multicolumn{3}{|c|}{$\begin{array}{l}\text { The rubber comprehensive index is } 0.131 \sim 0.18 \\
\text { The topographic comprehensive index is } 0.406 \sim \\
\text { The weather comprehensive index is } 0.226 \sim 0.30\end{array}$} & $R_{2}=[$ & $\left.\begin{array}{l}<0.131,0.18> \\
<0.406,0.49> \\
<0.226,0.309>\end{array}\right]$ \\
\hline & $0.1 \sim 0.2$ & \multicolumn{3}{|c|}{$\begin{array}{l}\text { The topographic comprehensive index is } 0.49 \sim 0.639 \\
\text { The weather comprehensive index is } 0.309 \sim 0.417\end{array}$} & $R_{3}=[$ & $\left.\begin{array}{l}<0.18,0.344> \\
<0.49,0.639> \\
<0.309,0.417>\end{array}\right]$ \\
\hline & $0.2 \sim 0.3$ & \multicolumn{3}{|c|}{$\begin{array}{l}\text { The topographic comprehensive index } \\
0.639 \sim 0.767 \\
\text { The weather comprehensive index is } 0.417 \sim 0.449\end{array}$} & $R_{4}=[$ & $\left.\begin{array}{l}<0.344,0.426> \\
<0.639,0.767> \\
<0.417,0.449>\end{array}\right]$ \\
\hline 5 & $>0.3$ & \multicolumn{3}{|c|}{$\begin{array}{l}\text { The rubber comprehensive index is larger than } 0.426 \\
\text { The topographic comprehensive index is larger than } \\
0.767 \\
\text { The weather comprehensive index is larger than } \\
0.449\end{array}$} & $R_{5}=$ & {$\left[\begin{array}{l}<0.426,1> \\
<0.767,1> \\
<0.449,1>\end{array}\right]$} \\
\hline $\begin{array}{l}\text { The } p \\
\text { influen }\end{array}$ & $\begin{array}{l}\text { area of each } \\
\text { or }\end{array}$ & $R=$ & Wind damage rate & $\left.\begin{array}{l}<0,1> \\
<0,1> \\
<0,1>\end{array}\right]$ & & \\
\hline
\end{tabular}

above level 10 occurred in 142 villages and towns. The maximum extreme value of wind occurred in Wenchang seven islands (the altitude of the observation station is $10 \mathrm{~m}$ ), with a wind speed of $46.8 \mathrm{~m} / \mathrm{s}$.

\subsubsection{Disaster evaluation}

Pre-disaster evaluation: according to the numerical weather prediction product at $08 \mathrm{am}$ of September 28th in 2011, the data within 72 hours by WRF model forecast are extracted with the rubber wind damage evaluation system. The data are then import into the database. The pre-disaster evaluation is started with reading the numerical weather prediction data, in the time period of 08 am of 28th to 08 am of 30th of September. The distribution of the weather factors is extracted and calculated based on the pre-disaster evaluation module. The proportions of level 1 to level 5 of disaster hazard are $11.57 \%, 17.49 \%, 61.32 \%, 8.19 \%$ and $.43 \%$, respectively. Level 3 is the most frequently occurring level, and the pre-disaster evaluation shows moderate hazard (Figure 1).

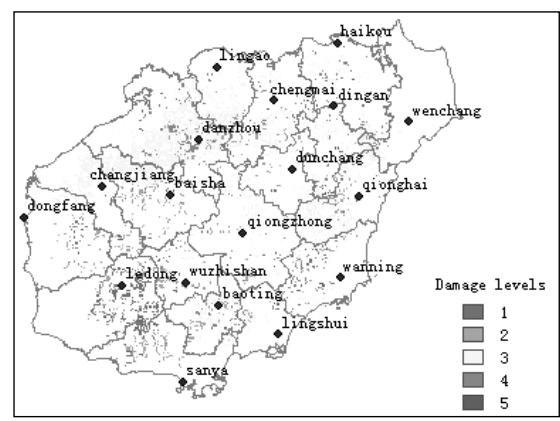

Fig.1. Prediction of damage levels of rubber plant based on numerical forecast data Post-disaster evaluation: using the 
Risk Analysis and Crisis Response in Big Data Era (RAC-16)

post-disaster evaluation module, the time period from 20 am of 28th to 20 am of 30th of September in 2011 is selected to perform the influence evaluation after the disaster. It can be known from the evaluation result that the whole process of strong typhoon Nesat has a great impact on the rubber plantation of Hainan Island. The disaster losses of rubber mainly come from the disaster of level 2 and level 3. The proportions of level 1 to level 5 of disaster hazard are $22.59 \%, 36.21 \%, 40.23 \%, 0.79 \%$ and $0.18 \%$, respectively. The comprehensive level of disaster hazard on rubber in Hainan Island for strong typhoon Nesat is classified as moderate (Figure 2). The rubber loss resulting from the disaster is located in the eastern, middle and northwest of Hainan Island, reaching a total of 1.40 million mu of private-run rubber plantation of Hainan province. Among them, the area of broken and flattened rubber is 98.1 thousand mu, leading to direct economic loss of 3.419 billion yuan (combined with the influence of No.19 strong tropical storm Nalgae). The cities and counties that suffered most seriously from typhoon are Danzhou (500 thousand mu), Chengmai (350 thousand mu), Anding (120 thousand $\mathrm{mu}$ ) and Qiongzhong (90 thousand $\mathrm{mu}$ ) The comparative analysis between system evaluation result and actual disaster indicates a good consistence and hence the objective reflection of disaster hazard by rubber wind damage evaluation system.

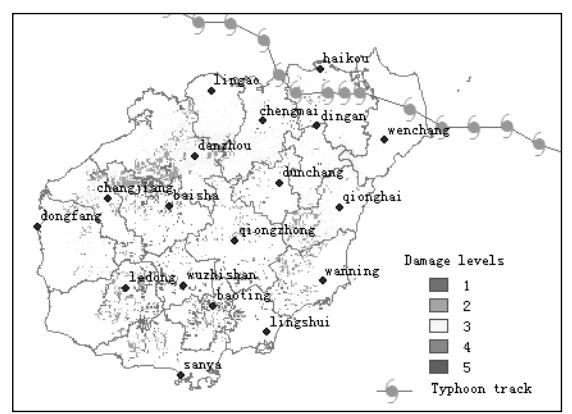

Fig.2. Post-disaster evaluation of damage levels of rubber plant

\section{Discussion}

(1)The wind damage grading standard of rubber tree is suitable for the investigation of land surface disaster, while the wind damage grading standard of rubber plantation is suitable for objective and fast evaluation covering large area. The relationship of the two is like the relationship between tree and forest and also between point and plane. The wind damage grading standard of rubber plantation obtains the relative level based on the analysis of historical rubber wind damage data, typhoon data and the research achievements of predecessors. So shortcomings are inevitable for preliminary research, which needs to be adjusted and improved by continually accumulating the wind damage cases in the future evaluation practice.

(2)Three factors (topographic factor, rubber factor and weather factor) are involved in the evaluation model, and the related information of the rubber provides the basic data of evaluation. The fixed-point observation of rubber plantation should be enhanced to realize the long-term, continuous, systematic and accurate accumulation of data and establish the rubber plantation observation network made up of the typical observation stations. The uniform and highly effective standardized management and the database construction should be enhanced and basic database should be updated every 1-2 years to provide more comprehensive and informative observation data for the typhoon disaster evaluation of rubber plantation. Thus, the optimization model for wind damage evaluation of rubber plantation with a better simulation effect can be established, which will enable a more detailed and objective description of the disaster process.

(3)In this research, through collecting and sorting the historical typhoon disaster data of rubber plantation, the evaluation model is established based on the statistical method and extension theory. The evaluation result is divided into 5 levels and we have achieved the wind 


\section{Risk Analysis and Crisis Response in Big Data Era (RAC-16)}

damage evaluation of rubber plantation on a quantitative, quick, macroscopic and objective basis. However, the evaluation model is only a kind of presentation model based on the statistical data. More efforts should be made in investigating the disaster formation mechanism model in the future.

\section{References}

[1] Lian Shihua, Discussion on the causes of wind damage of rubber tree. Chinese Journal of Tropical Crops, 1984, 5(1): 59-72.(in Chinese)

[2] Dana L.K. Hoag, Catherine M H Keske, Rebecca Goldbach. Risk Indviduality in Crisis Planning: the Case of Gender in Amercan Agriculture. Journal of Risk Analysis and Crisis Response, 2011, 1(1):21-28.

[3] Yang Shaoqiong, Mo Yeyong, Impact of typhoon on rubber tress:physiology of wind damaged trees and branch arrangement abnormality. Chinese Journal of Tropical Crops, 1995, 16(1):17-28. (in Chinese)

[4] Luo Jiaqin, Zhong Huazhou. Research briefing of wind damage on the rubber clone caused by No.9207 strong typhoon, Journal of Tropical Crop Science and Technology, 1992(6):80-81. (in Chinese)

[5] Li Zhiquan. Influence analysis and countermeasures on the rubber production of Hainan reclamation region after typhoon Damrey. Academic meeting exchange of special natural rubber committee of China Society of Tropical Crops, 2006-06-01:97-106. (in Chinese)

[6] Yu Wei, Zhang Mulan, Mai Quanfa et al. Damage of typhoon Damrey to the rubber industry in Hainan cultivated land and its countermeasures for future development. Chinese Journal of Tropical Agriculture, 2006,26(4):41-43. (in Chinese)

[7] Zhou Zhifeng. Chracteristics of tropical cyclone landing in Hainan Island and its influence on the rubber production of Hainan reclamation region. Meeting of activity of disaster weather system and its forecast technique, 2006 annual meeting of Chinese Meteorological Society, 2006-10-01: 667-671. (in Chinese)

[8] Ding Yan, Shi Peijun. Fuzzy risk evaluation model of typhoon disaster. Journal of Natural Disasters, 2002, 11(1):34-43

[9] Li Chunmei, Luo Xiaoling, Liu Jinluan et al. Application of analytical hierarchy process in the influence evaluation mode of tropical cyclone disaster . Journal of Tropical Meteorology, 2000, 6: 224-228. (in Chinese)

[10] Liang Biqi, Fan Qi, Yang Jie et al. Fuzzy mathematic evaluation of tropical cyclone disaster. Journal of Tropical Meteorology, 1999, 15(4): 305-311. (in Chinese)

[11] Lin Jisheng, Luo Jinling. Disaster evaluation and the forecast mode of tropical cyclone disaster landing in Guangzhou. Journal of Natural Disaster, 1995, 12(1): 92-97. (in Chinese)

[12] Chen Xiang. Risk evaluation and regionalization of typhoon disaster of Fujian Province. Ecological Magazine, 2007, 26(6): 961-966. (in Chinese)

[13] Liu Shaojun, Zhang Jinghong, He Zhengwei, Cai Daxin et al. Research on the evaluation model of typhoon disaster losses based on GIS , Journal of Catastrophology, 2010, 25(2): 64-67. (in Chinese)

[14] Sun Wei, Gao Feng, Liu Shaojun, Tian Guanghui et al. Extension method and its application in typhoon disaster loss evaluation in Hainan Island, Journal of Tropical Crops, 2010, 31(2): 319-324. (in Chinese)

[15] Wang wei1,Zhou chao,Du xin. The Research of a Hail Risk Evaluation under Imperfect Information. Journal of Risk Analysis and Crisis Response, 2011, 1(2):133-141. 